\title{
Traducción y traslado: aquellas otras palabras en el teatro de Stoppard
}

\author{
(4) Lucas Margarit \\ Facultad de Filosofía y Letras, Universidad de Buenos Aires, Argentina \\ lucasmargarit@gmail.com
}

Fecha de recepción: 03/03/2021. Fecha de aceptación: 04/05/2021

\begin{abstract}
Resumen
El uso de la expresión "sistema de representación" asume una variedad de posibilidades que se proyectan, incluso, fuera del plano de la palabra. De este modo se irá construyendo un entrecruzamiento de representaciones y de ecos que van dando forma a una puesta en escena y que necesita de la observación del espectador / lector para establecer dichos vínculos. En esta oportunidad nos centraremos en dos obras breves de Tom Stoppard para ver cómo pone en escena diferentes conflictos enfocados en el problema del lenguaje, de la traducción y de la representación. Dogg's Hamlet, Cahoot's Macbeth son dos piezas donde el tema de la referencia en el uso particular del lenguaje lleva a establecer un hiato entre la acción, la palabra y el espectador. Stoppard siempre estuvo interesado por los problemas surgidos por los "juegos de lenguaje" derivados de su lectura de Investigaciones Filosóficas de Ludwig Wittgenstein encontró en estas piezas breves una forma de representar sobre el escenario una teoría particular acerca de la palabra y de las posibilidades de comunicación.
\end{abstract}

Palabras clave: Stoppard, Shakespeare, representación, traducción, referencialidad, Cahoot's Macbeth, Dogg's Hamlet

\section{Translation and transfer: those other words in Stoppard's theater}

\begin{abstract}
The use of the expression "representation system" assumes a variety of possibilities that are even projected outside the register of the language. In this way, a mixture of representations and echoes that will built a shape to a staging and that requires the observation of the viewer / reader to establish such links. This time we will focus on two short plays by Tom Stoppard to see how he organizes a mise en scène with different conflicts focused on the problem of language, translation and representation. In Dogg's Hamlet, Cahoot's Macbeth the theme of the reference in the particular use of language leads to establishing a hiatus between the action, the word and the spectator. Stoppard was always interested in the problems arising from the "verbal games" derived from
\end{abstract}


his reading of Philosophical Investigations by Ludwig Wittgenstein and finds in these short pieces a way to represent on stage a particular theory about the word and the possibilities of communication.

Keywords: Stoppard, Shakespeare, representation, translation, referentiality, Cahoot's Macbeth, Dogg's Hamlet

\author{
Si se fijan cada salida \\ es una entrada a cualquier otro lugar. \\ Tom Stoppard
}

Trans/ducere. Si nos avenimos a la etimología, traducir es trasladar, guiar a través, es decir llevar de un lugar a otro; claro está que también podríamos considerar trasladar de un espacio de sentido a otro, o más arriesgado quizás, de un espacio de construcción de sentido a otro: traducir es siempre trasladar. Esto implica que hay un objeto que es llevado de un contexto determinado a otro, inclusive no necesariamente lingüístico. Desde esta perspectiva, quizá la metáfora funcione también como un modo particular de traducción. En teatro, traducir puede pensarse también como la trasposición del texto al espacio de representación, el escenario y todo lo que ello conlleva. Y aquí ya entramos en una disyuntiva con respecto a ese traslado, pasamos de una representación sugerente por sus ausencias en el texto -es decir, por lo general, lingüística- a una elección determinada por varios factores, uno de ellos, el director y la puesta, pero también los cuerpos, los objetos, etcétera. De allí que Sallenave afirmara que "tanto la traducción como la dirección implican la transposición a otra lengua o a otro sistema de expresión" (1982: 20).

Entonces si la transposición de un sistema de expresión a otro implica pensar cómo manifestar de otro modo aquella imagen, trama o idea que primero se trasladó al papel y de allí al escenario; entonces, toda puesta en escena es el resultado de un proceso de traducciones necesario. Ya el uso de la expresión sistema de representación asume una variedad que se proyecta inclusive al plano fuera de la palabra. De este modo se irá construyendo un entrecruzamiento de representaciones y de ecos que van dando forma a una representación dramática y que necesita de la observación del espectador/lector para establecer dichos vínculos. Por otra parte, no podemos olvidar que en este entramado la crítica genética puede tener un papel central en el proceso de constitución de sentidos con respecto al resultado final, pero esto ya entra en otro terreno de análisis, aunque también puede considerarse en ciertos puntos para reflexionar sobre el tema que estamos tratando. Un manuscrito puede ser el primer esbozo de una primera traslación de una idea determinada y también el anuncio de que ninguna obra es definitiva ${ }^{1}$.

Para comenzar, remontémonos al Renacimiento en Inglaterra y pensemos en el escenario vacío donde es claro el uso deíctico del lenguaje para señalar cada espacio donde se desarrolla la acción. La falta de marcas referenciales en ese escenario implica la necesidad de traducir por medio de los parlamentos de los personajes la materialidad ausente por la falta de escenografía. Hay ciertas convenciones que van sucediendo y creando un sentido determinado para denominar aquello que está ausente en escena: por ejemplo, un río, una recámara, un jardín. Como señala Dessen con respecto a estas convenciones durante el período isabelino: "For the scene to work, the actors must provide the timing and energy, the audience, the imaginative participation" [Para que la escena funcione, los actores deben proporcionar tiempo y energía, y el público 
participación imaginativa] (Dessen, 1984: 17. Todas las traducciones le pertenecen al autor del artículo): dos elementos necesarios para reconfigurar el texto que se traduce sobre el escenario, que se interpreta y por ello se produce el sentido. Inclusive el propio Dessen utiliza en varias oportunidades el término "translate into stage action" [traducir a la acción escénica] $(1984: 47,48,95,119)$ lo cual también nos indicaría que este proceso de transformación podría referirse claramente a traducir un sistema en otro donde la imaginación es, junto con la complicidad del espectador, el modo de constituir el sentido de la pieza.

La traducción, tal como la estamos considerando, también debe cumplir una lógica en ese traslado para encontrar el verosímil de la representación. Y esto se manifiesta en diferentes estratos de lo que estamos presentando. La representación debería tener una coherencia interna que determine el modo de complicidad al que nos hemos referido. Por ejemplo, si la obra necesita que el espectador perciba de algún modo el pensamiento de un personaje y, por ello, se enfrenta a una voz en off, el proceso de traducción implicará trasladar el texto escrito a una grabación y de allí a la puesta en escena para que ese proceso se transforme en la representación de un hecho inmediato llevado a cabo por el personaje: pensar. Con respecto a este ejemplo, estamos pensando en una obra de Samuel Beckett, Rockaby (1980). Es evidente que la imaginación y los modos de construcción de sentido del espectador son necesarios para poder completar el cuadro de este proceso siempre abierto.

La elección del período isabelino y de la obra de Beckett no fueron al azar, sino porque en esta oportunidad nos interesa trabajar también la problemática de la traducción (en estos términos) con un dramaturgo ligado de diferentes maneras a la obra de estos dos autores: Tom Stoppard, quien ya en una de sus primeras piezas, Rosencrantz and Guildenstern Are Dead (1967), alude de distinto modo a uno y a otro.

Esta obra se estrena en 1967 y va a subrayar claramente dos hipotextos, si seguimos la terminología que Genette demarcó en Palimpsestes (Genette, 1992:13). El más evidente es la tragedia de Shakespeare Hamlet, que ya está anunciado en el título, y el otro es Waiting for Godot de Samuel Beckett. En el caso de la obra de Beckett, no tenemos una cita o una alusión explícita, sino que lo que encontramos es una escena inicial con dos personajes insertos en una situación muy similar a la que se encuentran Vladimir y Estragon. Por ejemplo, la indeterminación de tiempo y espacio nos remite directamente a las acotaciones escénicas de Waiting for Godot. Por otra parte, con respecto a Hamlet, vemos que en la obra de Stoppard hay una inversión de valores y de jerarquías en el modo de constituir la representación, lo que permite que estos dos personajes -que en la obra de Shakespeare son secundarios-, aquí sean focalizados desde otra perspectiva y puedan ser considerados de otra manera: cumplen papeles protagónicos.

Asimismo, la obra nos muestra el otro lado de Hamlet; la acción se desplaza (se traslada) a las bambalinas, detrás del escenario donde se está representando (o está sucediendo) Hamlet. Ese atrás o fuera de escena de Hamlet es un lugar claramente indeterminado en el marco de la representación teatral en el período isabelino. Así, podríamos volver a considerar el tema de la traducción como traslado y resignificación. Y aquí creo que podríamos contemplar otra traslación en estos sistemas de sentido: el de la época, es decir, cómo la tragedia del siglo XVI es trasladada a la obra de Stoppard; inclusive hasta podríamos ver que se la traduce a un nuevo código de representación donde los valores se modifican y se invierten, y uno de los modos en que esto sucede es a partir del uso del inglés shakesperiano en consonancia con el inglés de un autor del siglo XX.

Estas apropiaciones y re-significaciones implican entonces llevar (traducir) un hipotexto a una nueva serie de códigos que responden a otra naturaleza, a otros inventarios 
y a diferentes relaciones. Otra de sus obras, After Magritte (1970), describe parte de la escena inicial del siguiente modo: "Most of the furniture is stacked up against the street door in a sort of barricade." [La mayoría de los muebles están apilados contra la puerta de la calle en una especie de barricada]. Como ya se ha señalado, por la exactitud y el detenimiento en cada detalle, la imagen que se conforma sobre el escenario parece trasladada de un cuadro del pintor belga. El elemento pictórico es así una referencia que estará presente en esta pieza, pero que también nos permitirá avanzar sobre otra serie de problemas con el lenguaje en la obra: el tema de la referencialidad. Las palabras en la obra de Magritte tienen una presencia ineludible, y la cuestión referencial es uno de los motivos centrales de las pinturas que conforman la serie "La trahison des images" [La traición de las imágenes] (1928-1929), como "Ceci ne est pas une pipe" o "La clef des songes" donde se pone en juego no sólo la relación palabra/objeto, sino también palabra/representación, al enfatizar la arbitrariedad y la frágil relación entre la cosa, la representación y los modos de uso del lenguaje².

A partir de estas referencias y de estas problemáticas que se entrecruzan en la obra de Stoppard, me interesa tomar dos obras muy breves y que a su vez interactúan, por un lado, entre sí y por otro, con dos tragedias shakesperianas: Dogg's Hamlet. Cahoot Macbeth, estrenada años después de After Magritte, en 1979. El autor comienza diciendo:

"The comma that divides Dogg's Hamlet, Cahoot's Macbeth also serves to unite two plays which have common elements: the first is hardly a play at all without the second, which cannot be performed without the first" [La coma que divide Dogg's Hamlet de Cahoot Macbeth también sirve para unir las dos obras que tienen elementos comunes: la primera difícilmente es una obra sin la segunda, y la segunda no puede representarse sin la primera] (Stoppard, 1996).

Tal como se señala en el extenso comentario inicial, estas obras nacen en la colaboración entre Tom Stoppard y la compañía de teatro "Dogg's Troupe" dirigida por su amigo Ed Berman. Existe una versión anterior de la primera pieza que se tituló Dogg's Our Pet, obra donde Stoppard ya pone en evidencia una serie de juegos con el lenguaje, prelingüísticos y corporales. Más adelante incorpora una versión de Hamlet de quince minutos, The (15 minutes) Dogg's Troupe Hamlet y luego una especie de "preámbulo" o "preludio" para una versión de Macbeth que Pavel Kohut presentaba en el espacio privado del salón de una casa para evitar la censura y el veto de dos actores checos prohibidos por el régimen, lo que se llamaba "Living Room Theater". Es decir que estas obras breves ya tienen una serie de antecedentes y juegos con el hipotexto shakesperiano (para el proceso de la creación de estas obras remitimos a Castagnino, 2005:128-130). Pero también anuncian una puesta en conflicto de la relación entre palabra y cosa.

Stoppard, que se había mostrado interesado por los problemas surgidos por los juegos de lenguaje derivados de su lectura del libro Investigaciones Filosóficas de Ludwig Wittgenstein, encontró en estas piezas breves una forma de representar sobre el escenario una teoría de origen filosófico acerca de la palabra y de la comunicación. Su intención era "the possibility of writing a play which had to teach the audience the language the play was written in" [la posibilidad de escribir una obra que tuviese que enseñar al espectador el lenguaje en que esa obra estaba escrita]. A partir de esta afirmación volvemos a pensar en la necesaria complicidad del espectador en el momento de la representación. Los cuatro personajes al comienzo de la obra, en un escenario casi vacío, están cargando y pasándose objetos. Inicio que interpela al espectador ya que al hablar exponen la arbitrariedad en el uso de palabras conocidas, dando cuenta de 
un uso de los significantes alejado del significado que se le suele atribuir en el idioma inglés. Tom Stoppard, entonces, para poder dar cuenta de este recurso con el que revierte las palabras y para que escapen de su sentido cotidiano, necesita presentar la traducción entre corchetes para el lector o para los encargados de la puesta, al lado del parlamento de los personajes, Abel, Barker, Charlie, en ese inglés que se ha denominado idioma dogg, término que tomamos del libro de María Inés Castagnino (2005, 130-131). Veamos un ejemplo:

\author{
ABEL: Cube! [Thanks!] \\ VOICE: (Off-stage) Brick! [Here!) \\ (CHARLIE tries to get the ball but ABEL won't let him have it.) \\ CHARLIE: Squire! [Bastard!] \\ (ABEL throws the ball to the unseen person in the wings-not where BAKER is.) \\ Daisy squire! [Mean bastard!] \\ ABEL: Afternoons! [Get stuffed!] \\ CHARLIE: (Very aggrieved.) Vanilla squire! [Rotten bastard!]
}

ABEL: ¡Cubo! [iGracias!]

VOZ: (Fuera del escenario) ¡Ladrillo! [iAquí!]

(CHARLIE intenta coger la pelota, pero ABEL no se lo permite).

CHARLIE: iEscudero! [iBastardo!]

(ABEL lanza la pelota a la persona invisible en los lados, no donde está BAKER).

¡Daisy escudero! [iMaldito bastardo!]

ABEL: ¡Tardes! [i]odete!]

CHARLIE: (Muy ofendido) iEscudero vainilla! [iputrefacto bastardo!]

Es evidente que el espectador -que en el momento de la representación no tendría acceso al texto-se encontrará ante una pieza que está poniendo en tela de juicio el idioma aprendido. La presencia de los dos idiomas en simultáneo en el texto evidencia una resignificación en el traslado de sentido: lo que parece conocido deviene en un intercambio que escapa de nuestra posibilidad de establecer coherencia en los parlamentos, a no ser que tengamos la traducción cerca. Las palabras conocidas son usadas con un sentido diferente, el signo lingüístico se reacomoda en otra serie de significados. Pareciera que los personajes hablaran en un código particular que excluye al espectador hasta que pueda traducir esas palabras enunciadas en idioma dogg, lo cual implica que no hay un azar en el uso de esas palabras, sino que responden a una especie de lógica, ya que respetan el significado dado desde el inicio a lo largo de toda la pieza. Wittgenstein señala que "el significado de una palabra es su uso en el lenguaje" (2002: 43); por lo tanto, el significado de las palabras que usan los personajes de esta obra se va constituyendo en una zona de códigos que se va transformando en un hábito comunicacional.

Esto nos conduce a una pregunta: ¿qué sucede con el idioma de origen y el de llegada? En este caso, no podemos dejar de dudar que se traduce en el texto que leemos del otro inglés al inglés habitual y conocido. Lo que se manifiesta entonces es un hiato entre palabra y sentido que se radicaliza cuando encontramos en medio de este otro idioma algunos neologismos conviviendo con palabras inglesas. El espectador percibe palabras en inglés, pero en otro ámbito de constitución de sentido y por el contexto tiene que re-traducir lo que los personajes están diciendo. Aquí lo que cambia es el uso de las palabras, no su significante, sino su forma de uso, instancia que Stoppard recupera en estos diálogos entre los personajes, quienes hacen un uso diferenciado de las palabras. Es un proceso que implica repetición, asimilación y uso: un "juego de lenguaje" (Wittgenstein, 2002:123, 124). Otro aspecto interesante es que la obra da pistas equívocas para el acercamiento a ese lenguaje. Hay un personaje que se une a los primeros, Easy, quien habla inglés y establece una relación equívoca: cuando Dogg dice "plank" [tablón 
en inglés] y le arrojan un tablón, cree (junto al público) que "plank" significa, para el idioma dogg, tablón. Esta situación se repite tres veces en que el significante "plank" parece establecer la misma referencia que el inglés habitual. Sin embargo, el equívoco aparece cuando se dice una vez más y la referencia es un bloque. Easy queda desconcertado y la lógica que ha utilizado se desvanece en el uso que hacen de las palabras los otros personajes. La traducción, entonces, sería algo similar a recibido, lo cual se inserta perfectamente en la lógica de los diálogos entre estos personajes.

De a poco los espectadores (junto a Easy) entran en esa lógica y empiezan a comprender y descifrar (traducir) algunos de los parlamentos en dogg. Al final los espectadores (y Easy) entran en esa especie de código, comprendiendo, aunque sea parcialmente y por deducción el sentido de cada palabra enunciada. Los cuatro personajes armaron una escenografía en segundo grado, se va a hacer una entrega de premios y luego a representar un Hamlet abreviado en inglés. Vemos de este modo una nueva traslación de un espacio de representación a otro, un Hamlet inserto en otra obra, lo que implica una transformación y una resignificación y una apropiación.

La otra obra, Cahoot's Macbeth, como ya señalamos, remite a una situación política relacionada con el dramaturgo checo Pavel Kohout. Así se nos cuenta en la introducción a las obras:

A year later Kohout wrote to me: 'As you know, many Czech theatre-people are not allowed to work in the theatre during the last years. As one of them who cannot live without theatre I was searching for a possibility to do theatre in spite of circumstances. Now I am glad to tell you that in a few days, after eight weeks rehearsals - a LivingRoom Theatre is opening, with nothing smaller but Macbeth.

[Un año después, Kohout me escribió: “Como sabe, a muchos checos dedicados al teatro no se les permitió trabajar en las salas durante los últimos años. Como uno de ellos, que no pueden vivir sin el teatro, busqué la posibilidad de hacer teatro a pesar de las circunstancias. Ahora me alegra decirle que en unos días, después de ocho semanas de ensayos, se inaugurará un Living-Room Theatre, con nada más ni nada menos que Macbeth]

Y justamente la pieza de Stoppard trata de esta situación que cuenta Kohout. En ambas obras una pieza de Shakespeare está reducida por un límite de tiempo y espacio (y de palabras). Por otra parte, los usos del lenguaje se irán contaminando unos con otros. Pasemos a Cahoot's Macbeth. El inicio, como en la obra de Shakespeare, nos muestra la escena de las brujas, con truenos y relámpagos:

The action takes place in the living room of a flat.

Thunder and lightning. Three WITCHES in minimal light.

[La acción se desarrolla en el salón de un departamento.

Truenos y relámpagos. Tres BRUJAS con muy poca luz].

El comienzo con las palabras de las brujas nos lleva a una brevísima versión de Macbeth en el espacio limitado del interior de una casa. Las palabras de las brujas revelan un nuevo traslado: de la tragedia de Shakespeare a la pieza de "living room" de Stoppard. Para el espectador/lector es evidente la apropiación, los parlamentos son de una puesta en escena reducida de Macbeth, es decir que son fragmentos que están dando una estructura a la pieza en la obra de Stoppard. Aquí se entrecruzan varias textualidades y registros, la obra de Shakespeare -que está siendo representada en el salón- es interrumpida durante la representación del segundo acto por la aparición de un inspector de la policía. 


\author{
MACBETH: Wake Duncan with thy knocking! (Sharp rapping.) \\ I would thou couldst! \\ (They leave. The knocking off-stage continues. A door, off-stage, opens and closes. \\ The door into the room opens and the INSPECTOR enters an empty room. He seems \\ surprised to find himself where he is. He affects a sarcastic politeness.) \\ INSPECTOR: Oh-l'm sorry-is this the National Theatre? \\ (A woman, the HOSTESS, approaches through the audience.) \\ HOSTESS: No.
}

[MACBETH: ¡Despierta a Duncan con tus golpes! (Golpes agudos.)

¡Ojalá pudieras!

(Se van. Continúan los golpes fuera del escenario. Una puerta, fuera del escenario, se abre y se cierra. La puerta del salón se abre y el INSPECTOR entra en una habitación vacía. Parece sorprendido de encontrarse donde está. Con un sarcástico tono de cortesía.) INSPECTOR: ¡Oh!, lo siento, ¿es este el Teatro Nacional? (Una mujer, la ANFITRIONA, se acerca entre el público.) ANFITRIONA: No.]

Desde esta interrupción los parlamentos de los personajes se entrelazan explicitando los límites borrosos entre la representación dramática y lo real de la situación. Ante las preguntas del inspector de policía las respuestas estarán en boca de Macbeth al enunciar los parlamentos de la obra de Shakespeare, creando una clara ambivalencia que nos lleva a la pregunta ¿quién habla, el actor o el personaje?

Más adelante, aparece nuevamente Easy, el personaje que estaba tratando de comprender y de interpretar el idioma Dogg en la pieza anterior. En esta pieza lo habla fluidamente, razón por la cual nadie puede entender lo que dice. Posteriormente, por azar, este personaje deviene en el actor que representa a Banquo al entrar por una ventana al salón de la representación. Estos límites borrosos entre los niveles de representación permiten la traducción de la escena shakesperiana a otros registros semánticos. En la obra de Stoppard, nos encontraremos un Macbeth atravesado por los conflictos políticos del siglo XX, por el humor, por el idioma Dogg, etc. Este movimiento de traslación es también un modo de resignificación que se produce por la labilidad manifiesta de la obra shakespeariana y por cómo la reescribe Stoppard. El inspector luego intenta comprender a Easy, pero el idioma Dogg nuevamente aparece como incomprensible para algunos personajes.

EASY: Useless, git ... [Afternoon, sir ...]

INSPECTOR: Who are you, pig-face?

(INSPECTOR grabs him. EASY yelps and looks at his watch.)

EASY: Poxy queen! [Twenty past ouch.]

Marzipan clocks! [Watch it!]

INSPECTOR: What?

HOSTESS: He doesn't understand you.

INSPECTOR: What's that language he's talking?

HOSTESS: At the moment we're not sure if it's a language or a clinical condition.

[EASY : Inútil, idiota ... [Buenas tardes, señor ...]

INSPECTOR: ¿Quién eres tú, cara de cerdo?

(EI INSPECTOR lo agarra. EASY grita y mira su reloj.)

FÁCIL: ¡Poxy queen! [Veinte pasados ayes.]

¡Relojes de mazapán! [iMíralo!]

INSPECTOR: ¿Qué?

ANFITRIONA: No te entiende. 
INSPECTOR: ¿Cuál es ese idioma que está hablando?

ANFITRIÓN: Por el momento, no estamos seguros de si se trata de un idioma o de una afección clínica].

Nuevamente la barrera idiomática y la presencia de la traducción al inglés. Ya en ese momento, el espectador está más familiarizado con la situación y comprende de manera más directa y clara alguna de estas palabras que pronuncia Easy.

En estas obras podríamos pensar una serie de maneras de representar los conflictos dramáticos, por un lado, la traslación de algunos conceptos tomados de la filosofía de Wittgenstein y el otro la puesta en escena del problema de la relación palabra objeto que remite también a un problema de traducción y de reflexionar sobre los significantes en el momento mismo de la comunicación. Se traduce también para comunicar. Asimismo, no podemos dejar de lado el perfil político de estas piezas con respecto a la censura y a las necesidades de decir de otro modo para evadirla. Stoppard enfatiza estas problemáticas a través del juego con el sentido de las palabras y lo hace a través de los usos del idioma dogg, del inglés isabelino y del inglés del lector/espectador. De allí que podamos sospechar que la traducción no es sólo la que aparece en el texto entre corchetes en la edición impresa, sino también la que se produce por el uso y la referencia visual en la puesta en escena. La entrada de Easy en la primera pieza y del Inspector en la segunda ponen en tensión ese uso de lenguaje en tanto alteridades con respecto a esos usos del lenguaje. Dice Anthony Jenkins al referirse a Cahoot's Macbeth:

La figura clave en todo esto es el Inspector. Su llegada al apartamento se asemeja a la de Easy en la escuela en la primera parte, ya que ambos se enfrentan a un lenguaje (Dogg y Shakespeare) que, se dan cuenta, tiene un significado oculto (1989:158).

Siempre una palabra se resignifica en el contexto y Stoppard lleva esta premisa a tal extremo que también nos lleva a pensar durante la lectura o la puesta en el proceso mismo de traslación o de traducción para ir conformando un sentido. Es el mismo acto de trastrocamiento del lenguaje en el uso el que proyecta una traducción plausible en el momento de la acción. Los personajes interpretan aquellas palabras que están fuera de su sistema e intentan unir palabra y acción para encontrar un sentido a lo que perciben. Del mismo modo que Macbeth interpreta erróneamente las profecías finales de las tres brujas, aquel significado oculto que el personaje shakesperiano no comprende, es quizá el mismo que nosotros intentamos comprender desde el inicio de Dogg's Hamlet. Desde una perspectiva más cercana la ironía y a cierto humor, Tom Stoppard confirmaría quizá que todo acto de interpretación no es más que una continua traducción parcial de aquello que logramos ver y oír sobre un escenario. 


\section{Bibliografía}

» Berger, J. (1987). “Magritte y lo imposible”, en: Berger, J. Mirar. Madrid: Hermann Blume.

" Bocardo, E. (2000). “La Trahison des images”, Thémata. Revista de Filosofía № 23.

"Castagnino, M. I. (2005). Tom Stoppard. El camaleón y sus voces, Buenos Aires: Atuel.

»Dessen, A. C. (1984) Elizabethan stage conventions and modern interpreters, Cambridge: CUP.

» Foucault, M. (1993). Esto no es una pipa: ensayo sobre Magritte. Barcelona: Anagrama.

" Genette, G. (1992). Palimpsestes: La littérature au second degré, París: Éditions du Seuil.

"Grésillon, A. (1994). Éléments de critique génétique : Lire les manuscrits modernes. París : PUF.

" Jenkins, A. (1989). The Theatre of Tom Stoppard, Melbourne: Cambridge University Press.

» Magritte, R. (2009) Écrits complets. París: Flammarion.

»Marchán Fiz, S. (2002). “Las palabras, las imágenes y las cosas: René Magritte”. En: Bonet, J. M. El surrealismo y sus imágenes. La Rioja: Universidad de la Rioja.

»Margarit, L. (1998). “¿Qué significa leer un manuscrito?”, en Dubatti, J. (comp.). Beckett en Argentina. Buenos Aires: Eudeba.

»Sallenave, D. (1982). “Traduire et mettre en scène”, Acteurs, №1.

»Stoppard, T. (1996) Plays, Volume 1, London: Faber \& Faber.

»Wittgenstein, L. (2002). Investigaciones filosóficas, trad. Alfonso García y Ulises Moulines, Barcelona: Crítica. 